\title{
Registro de Oncideres saga (Coleoptera: Cerambycidae) em Peltophorum dubium (Leguminosae) no Município de Trombudo Central, Santa Catarina, Brasil
}

\author{
Gabriely Koerich Souza ${ }^{\bowtie}$, Tiago Georg Pikart¹, Filipe Christian Pikart² \& José Cola Zanuncio ${ }^{1}$
}

1. Universidade Federal de Viçosa, e-mail: gaby.florestal@gmail.com (Autor para correspondência ${ }^{\bowtie}$ ), tiago.florestal@gmail.com, zanuncio@ufv.br. 2. Universidade do Estado de Santa Catarina, e-mail: filipe.17@gmail.com.

EntomoBrasilis 5 (1): 75-77 (2012)

Resumo. Peltophorum dubium (Sprengel) Taubert (Leguminosae) tem sido empregada com sucesso na arborização de praças, parques e rodovias, por apresentar flores amarelas formando vistosas panículas terminais e folhagem densa proporcionando ótima sombra. Entretanto, besouros serradores têm sido considerados uma potencial ameaça à arborização urbana no Brasil, causando danos a várias espécies botânicas ornamentais. O objetivo desse estudo foi registrar e caracterizar o ataque por besouros serradores em plantas de P. dubium em Trombudo Central, Santa Catarina, Brasil entre novembro de 2006 e janeiro de 2007. Os danos foram observados em 12 árvores utilizadas na arborização urbana do município. Durante o período de levantamento, 27 galhos roletados foram coletados, sendo o diâmetro médio dos mesmos de $6,35 \mathrm{~cm}$. Este é o primeiro registro do besouro serrador Oncideres saga (Dalman) danificando plantas de P. dubium no Brasil.

Palavras-chave: Arborização urbana; Besouro serrador; Canafístula; Praga florestal.

\section{Report of Oncideres saga (Coleoptera: Cerambycidae) in Peltophorum dubium (Leguminosae) in Trombudo Central, Santa Catarina State, Brazil}

Abstract. Peltophorum dubium (Sprengel) Taubert (Leguminosae) has been used successfully for landscaping squares, parks and roads, due its yellow flowers forming terminal panicles and dense foliage providing excellent shade. However, twig girdlers have been considered a potential threat to the urban landscaping in Brazil, damaging many ornamental plant species. The aim of this study was to record the attack of twig girdlers in plants of P. dubium in Trombudo Central, Santa Catarina State, Brazil between November 2006 and January 2007. Damage was observed on 12 trees used in the urban landscaping of the city. During the survey period, 27 girdled branches were collected with an average diameter of $6.35 \mathrm{~cm}$. This is the first record of the twig girdler Oncideres saga (Dalman) damaging plants of $P$. dubium in Brazil.

Keywords: Canafístula; Forest insect pest; Twig girdler; Urban landscaping.

$\boldsymbol{P}$ eltophorum dubium (Sprengel) Taubert (Leguminosae), conhecida popularmente como canafístula, ibirá ou angico-amarelo, apresenta extensa distribuição natural desde a Paraíba até o Rio Grande do Sul (CARvalho 2003). Essa espécie apresenta-se frequente em todo o domínio da floresta estacional semidecidual, abundante em formações secundárias, mas com poucos indivíduos ocupando o estrato dominante do dossel em floresta primária (Donadio \& Dematrê 2000). Possui madeira moderadamente pesada (densidade $0,69 \mathrm{~g} \cdot \mathrm{cm}^{-3}$ ) rija e de longa durabilidade, sendo utilizada na construção civil, indústria de móveis e construção naval (REITZ et al. 1978; BACKEs et al. 2002; CARVALHO 2003). Como planta rústica e de rápido crescimento, é também utilizada para a recuperação de áreas degradadas. Além disso, tem sido empregada com sucesso na arborização de praças, parques e rodovias, por apresentar flores amarelas formando vistosas panículas terminais e folhagem densa, proporcionando ótima sombra (Donadio \& DematTê 2000).

Besouros da família Cerambycidae (Coleoptera) e subfamília Lamiinae, conhecidos popularmente como serradores, são extremamente danosos a atividade florestal, uma vez que a fêmea desses insetos usa as mandíbulas para roletar e seccionar plantas jovens ou galhos para utilizar como substrato para oviposição (Rice 1989; Caraglio et al. 2001). Dentre as espécies mais importantes, Oncideres saga (Dalman) tem sido considerada uma potencial ameaça à arborização urbana no Brasil, causando danos a várias espécies botânicas ornamentais, como Acacia mangium Willdenow (Leguminosae), Albizia lebbeck (Linnaeus) Bentham (Leguminosae), Cassia fistula Linnaeus (Leguminosae), Casuarina equisetifolia Linnaeus (Casuarinaceae), Delonix regia (Bojer ex Hooker) Rafinesque (Leguminosae), Inga edulis Martius (Leguminosae), Leucaena leucocephala (Lamarck) de Wit (Leguminosae) e Parapiptadenia rigida (Bentham) Brenan (Leguminosae) (Coutinho et al. 1998; CoRdeiro et al. 2010). Os principais danos causados às plantas são a alteração da arquitetura da copa, redução da atividade fotossintética e produção de sementes, interferindo na capacidade de reprodução das espécies e abrindo porta de entrada para microorganismos fitopatogênicos (CoutinHo 1997).

O objetivo desse estudo foi registrar o ataque em plantas de $P$. dubium por besouros serradores, em Trombudo Central, Santa Catarina, Brasil.

O roletamento de galhos de $P$. dubium por besouros serradores foi observado em Trombudo Central, Santa Catarina, Brasil ( $\left.27^{\circ} 18^{\prime} 11^{\prime \prime} \mathrm{S}, 49^{\circ} 47^{\prime} 41^{\prime \prime} \mathrm{W}\right)$ entre novembro de 2006 e janeiro de 2007. Inspeções semanais foram realizadas para localizar e 
cadastrar plantas de $P$. dubium que apresentavam características de ataque por besouro serrador. As avaliações foram feitas pela observação direta de besouros roletando galhos e de galhos recémroletados. Danos foram observados em 12 árvores utilizadas na arborização urbana do município e galhos recém-roletados e os insetos que se encontravam sobre estes foram coletados. $\mathrm{O}$ número total e o diâmetro médio dos galhos roletados e o número de insetos coletados foram avaliados. O diâmetro dos ramos cortados foi mensurado na base, utilizando-se fita métrica. Os indivíduos coletados foram montados e depositados no Museu de Entomologia do Centro de Ciências Agroveterinárias da Universidade do Estado de Santa Catarina em Lages, Santa Catarina, Brasil. Os indivíduos foram identificados como O. saga (Coleoptera: Cerambycidae), de acordo com Dillon \& Dillon (1946).

Durante o período de levantamento, 27 galhos roletados por $O$. saga foram coletados, com diâmetro médio de $6,35 \mathrm{~cm}$. No mesmo período, 14 adultos de $O$. saga foram coletados, sendo cinco machos e nove fêmeas. Apenas fêmeas desse besouro serrador realizam o trabalho de corte dos galhos, que pode durar vários dias, dependendo do diâmetro dos mesmos (MARICONI 1971). Assim que o galho é roletado, macho e fêmea copulam sobre o mesmo (Figura 1), podendo haver mais de um casal copulando por galho. Em seguida, a fêmea faz pequenas incisões nos ramos onde irá realizar a postura dos ovos (CARAGLIo et al. 2001).

Apesar de $O$. saga ter sido registrado em mais de 20 espécies botânicas em todo o Brasil (SiLva et al. 1968), este é o primeiro registro deste besouro serrador danificando plantas de P. dubium. Besouros do gênero Oncideres apresentam comportamento de uso da planta hospedeira especializado (PAULINo Neto et al. 2005) $\mathrm{e}$, por isso, este inseto pode se tornar uma praga importante em locais onde a arborização urbana apresenta predominância de hospedeiros da mesma espécie.

\section{AGRADECIMENTOS}

Ao "Conselho Nacional de Desenvolvimento Científico e Tecnológico (CNPq)", "Coordenação de Aperfeiçoamento de Pessoal de Nível Superior (CAPES)" e "Fundação de Amparo à Pesquisa do Estado de Minas Gerais (FAPEMIG)" pelo apoio financeiro.

\section{REFERÊNCIAS}

Backes, P. \& B. Irgang, 2002. Árvores do Sul: guia de identificação \& interesse ecológico. Porto Alegre, Pallotti, 326p.

Caraglio, Y., E. Nicolini \& P. Petronelli, 2001. Observations on the links between the architecture of a tree (Dicorynia guianensis Amshoff) and Cerambycidae activity in French Guiana. Journal of Tropical Ecology, 17: 459-463.

Carvalho, P.E.R., 2003. Espécies arbóreas brasileiras. Brasília, Embrapa Informação Tecnológica; Colombo, Embrapa Florestas, 1039p.

Cordeiro, G., N. Anjos \& A.G. Carvalho, 2010. Entomofauna associada a galhos de Acacia mangium Willd. roletados por Oncideres saga (Dalman) (Coleoptera: Cerambycidae). EntomoBrasilis, 3: 22-24.

Coutinho, C.L., 1997. Oncideres saga (Dalman, 1823) (Coleoptera, Cerambycidae) em arborização com Albizzia lebbeck Benth. Dissertação (Mestrado em Ciências Ambientais e Florestais) - Universidade Federal Rural do Rio de Janeiro. 112 p.

Coutinho, C.L., A.G. Carvalho, E.S. Oliveira \& B.G.A. Veiga, 1998. Oncideres saga (Dalman,1823) (Coleoptera, Cerambycidae) e a arborização urbana em Seropédica, RJ. Floresta e Ambiente, 5: 50-54.

Dillon, L.S. \& E.S. Dillon. 1946. The tribe Onciderini (Coleoptera: Cerambycidae). Part II. Reading Public Museum and Art Gallery, Scientific Publications, Reading, 6: 189-413.

Donadio, N.M.M. \& M.E.S.P. Demattê, 2000. Morfologia de

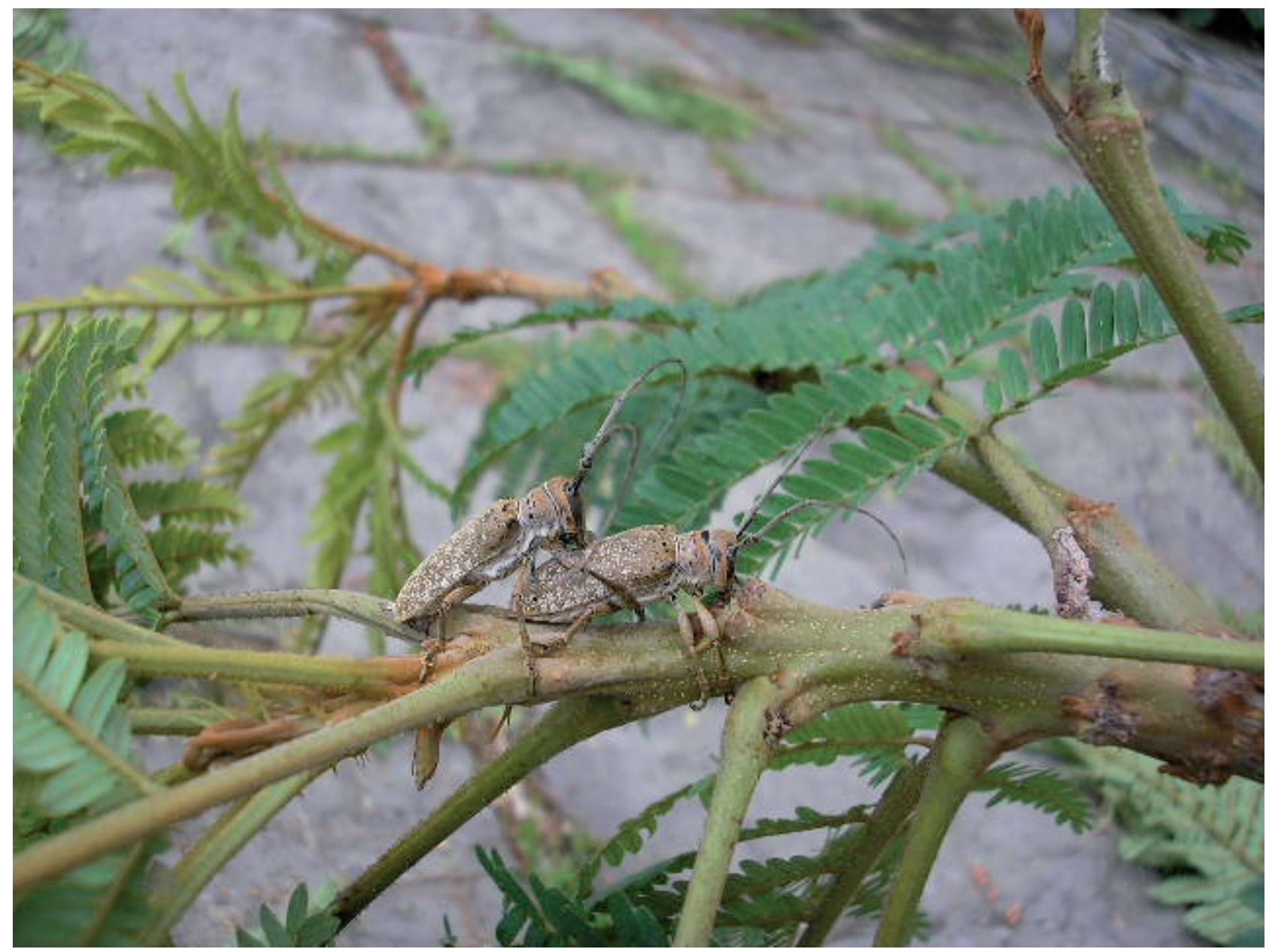

Figura 1: Casal de Oncideres saga (Dalman) em cópula sobre ramo de Peltophorum dubium (Leguminosae) roletado. Trombudo Central, Santa Catarina, Brasil. 
frutos, sementes e plântulas de Canafístula (Peltophorum dubium (Spreng.) Taub.) e Jacarandá-da-Bahia (Dalbergia nigra (Vell.) Fr.All. ex Benth.) - Fabaceae. Revista Brasileira de Sementes, 22: 64-73.

Mariconi, F.A.M., 1971. Inseticidas e seu emprego no combate às pragas. 3 Ed. São Paulo, A Gazeta Maçônica, 305 p.

Paulino Neto, H.F., G.Q. Romero \& J. Vasconcellos Neto, 2005. Interactions between Oncideres humeralis Thomson (Coleoptera: Cerambycidae) and Melastomataceae: hostplant selection and patterns of host use in south-east Brazil. Neotropical Entomology, 34: 7-114.

Reitz, R., R.M. Klein \& A. Reis, 1978. Projeto madeira de Santa Catarina. Sellowwia, n.34/35: 525.
Rice, M.E., 1989. Branch girdling and oviposition biology of Oncideres pustulatus (Coleoptera: Cerambycidae) on Acacia farnesiana. Annals of the Entomological Society of America, 82: 181-186.

Silva, A.G.A., C.R. Gonçalves, D.M. Galvão, A.J.L. Gonçalves, J. Gomes, M.N. Silva \& L. Simoni, 1968. Quarto catálogo dos insetos que vivem nas plantas do Brasil, seus parasitos e predadores. $1^{\mathrm{o}}$ Tomo, $2^{\mathrm{a}}$ Parte. Rio de Janeiro, Ministério da Agricultura, 265p.

\section{Recebido em: 05/04/2011}

Aceito em: 11/10/2011

\section{Como citar este artigo:}

Souza, G.K., T.G. Pikart, F.C. Pikart \& J.C. Zanuncio, 2012. Registro de Oncideres saga (Coleoptera: Cerambycidae) em Peltophorum dubium (Leguminosae) no Município de Trombudo Central, Santa Catarina, Brasil. EntomoBrasilis, 5(1): 75-77.

Acessível em: http://www.periodico.ebras.bio.br/ojs/index.php/ebras/article/view/150
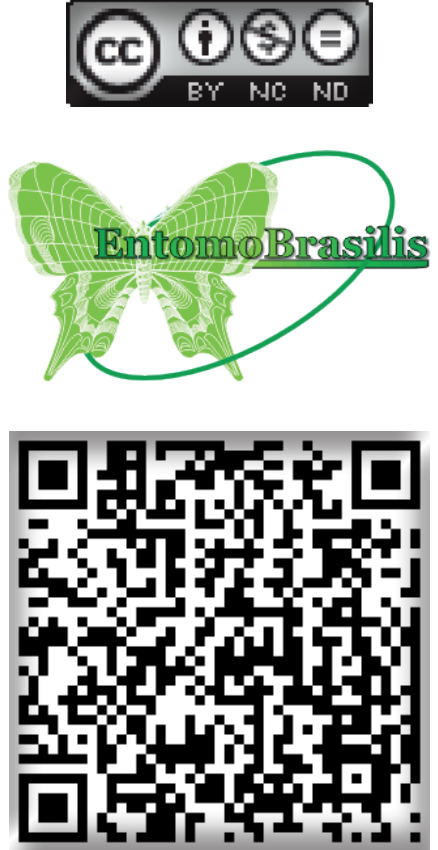